\title{
Hair follicle-associated-pluripotent (HAP) stem cells
}

\author{
Yasuyuki Amoh ${ }^{\mathrm{a}}$ and Robert M. Hoffman ${ }^{\mathrm{b}, \mathrm{c}}$ \\ ${ }^{\mathrm{a} D e p a r t m e n t ~ o f ~ D e r m a t o l o g y, ~ K i t a s a t o ~ U n i v e r s i t y ~ S c h o o l ~ o f ~ M e d i c i n e, ~ M i n a m i ~ W a r d, ~ S a g a m i h a r a, ~ J a p a n ; ~}{ }^{\mathrm{b} A n t i C a n c e r, ~ I n c ., ~ S a n ~ D i e g o, ~ C A, ~ U S A ; ~}$ \\ 'Department of Surgery, University of California San Diego, San Diego, CA, USA
}

\begin{abstract}
Various types of stem cells reside in the skin, including keratinocyte progenitor cells, melanocyte progenitor cells, skin-derived precursors (SKPs), and nestin-expressing hair follicle-associated-pluripotent (HAP) stem cells. HAP stem cells, located in the bulge area of the hair follicle, have been shown to differentiate to nerve cells, glial cells, keratinocytes, smooth muscle cells, cardiac muscle cells, and melanocytes. HAP stem cells are positive for the stem-cell marker CD34, as well as K15-negative, suggesting their relatively undifferentiated state. Therefore, HAP stem cells may be the most primitive stem cells in the skin. Moreover, HAP stem cells can regenerate the epidermis and at least parts of the hair follicle. These results suggest that HAP stem cells may be the origin of other stem cells in the skin. Transplanted HAP stem cells promote the recovery of peripheral-nerve and spinal-cord injuries and have the potential for heart regeneration as well. HAP stem cells are readily accessible from everyone, do not form tumors, and can be cryopreserved without loss of differentiation potential. These results suggest that HAP stem cells may have greater potential than iPS or ES cells for regenerative medicine.
\end{abstract}

ARTICLE HISTORY

Received 2 June 2017

Accepted 1 July 2017

\section{KEYWORDS}

Hair follicle; nestin; stem cell; bulge area; differentiation; cardiac muscle cell; neuron

\section{Introduction}

The mammalian epidermis contains several self-renewing compartments. ${ }^{1-3}$ Stem cells of the epidermis include keratinocyteprogenitor cells from the hair follicle ${ }^{4}$ melanocyte-progenitor cells, ${ }^{5}$ nerve stem cells in the skin, ${ }^{6}$ stem cells in the eccrine gland, ${ }^{7}$ skin-derived precursors (SKPs) located in the dermal papilla, ${ }^{8,9}$ and nestin-expressing hair follicle-associated-pluripotent (HAP) stem cells located in the bulge area of the hair follicle. $^{8-10}$ Keratinocyte progenitor cells in the hair follicle differentiate only to keratinocytes. Melanocyte progenitor cells ${ }^{5}$ differentiate only to melanocytes. The nerve stem cells in the skin, stem cells in the eccrine gland, and SKPs in the dermal papilla differentiate to various types of cells.

\section{Epidermal stem cells and keratinocyte-progenitor cells in the hair follicle bulge area}

The hair follicle cycles between growth (anagen), regression (catagen), and resting (telogen) phases throughout life. ${ }^{11}$ Stem cells located in the hair-follicle bulge area give rise to follicle structures during each anagen phase. Taylor et al. ${ }^{12}$ reported that hair-follicle bulge stem cells are potentially bipotent because they can give rise both hair-follicle and epidermal cells. Other studies $^{13}$ have shown that the bulge-area stem cells differentiate into hair-follicle matrix cells, sebaceous-gland basal cells, and epidermis. Fuchs ${ }^{1}$ engineered transgenic mice to express histone H2B-green fluorescent protein (GFP) controlled by a tetracycline-responsive regulatory element as well as a keratinocyte-specific promoter. During anagen, newly-formed GFP-positive populations derived from the bulge stem cells formed the outerroot sheath hair-matrix cells as well as inner root-sheath cells. In response to wounding, some GFP-labeled stem cells migrated from the bulge, and proliferated to repopulate the infundibulum and epidermis. ${ }^{1}$ Morris et al. ${ }^{14}$ used a keratinocyte promoter to drive GFP expression in the hair-follicle bulge cells to show that bulge cells in adult mice generate all epithelial cell types within the intact follicle and hair during normal hair-follicle cycling.

\section{Skin-derived precursors (SKPs)}

Toma et al. ${ }^{8}$ reported that SKPs, can proliferate and differentiate in culture to produce neurons, glia, smooth muscle cells, and adipocytes. The exact location of the SKPs was not identified in that report. Fernandes et al..$^{9}$ later reported the presence of pluripotent neural crest stem cells in the dermal papillae of adult mammalian hair follicles which were claimed to be SKPs.

\section{Melanocyte progenitor cells}

Melanocytes (pigment cells) in hair follicles proliferate and differentiate closely coupled to the hair cycle. Nishimura et al. ${ }^{15}$ reported that stem cells of the melanocyte lineage could be identified, using Dct-lacZ transgenic mice, in the lower permanent portion of mouse hair follicles throughout the hair cycle. The population in this region that satisfied the criteria for stem cells, being immature, slow cycling, self-maintaining and fully competent in regenerating progeny upon activation at early anagen. Nishimura claimed that the disappearance of melanocyte stem cells is the cause of age-related hair graying. ${ }^{5,15}$ 


\section{Stem cells in the eccrine gland}

Multipotent nestin-positive stem cells reside in the stroma of human eccrine and apocrine sweat glands. ${ }^{7}$ Nagel et al. ${ }^{7}$ have shown that human sweat-gland stroma contains nestin-positive stem cells. Isolated sweat gland stroma-derived stem cells (SGSCs) proliferated in vitro and expressed nestin in $80 \%$ of the cells. Nagel et al. ${ }^{7}$ determined the precise localization of nestin-positive cells in both eccrine and apocrine sweat glands of human axillary skin. SGSCs demonstrated multipotent differentiation. ${ }^{7}$ Mehnert et al. ${ }^{16}$ showed the potential of SGSCs for peripheral-nerve regeneration in vitro.

\section{Discovery of (HAP) stem cells}

We originally reported that nestin, a marker for neural progenitor cells, is also expressed in cells of the hair-follicle bulge using mice that expressed nestin-driven green fluorescent protein (NDGFP). ${ }^{10}$ The ND-GFP cells behave as stem cells, differentiating to form much of the hair follicle during each hair growth cycle.

HAP stem cells have round/oval-shaped bodies with a typical diameter of $7 \mu \mathrm{m}$ and 2-three long elongated processes containing club-like bodies. The nestin-expressing HAP stem cells co-expressed S100, a Schwann cell marker, and p75, a neuralcrest and immature Schwann-cell marker, as well as nestin. The club bodies of the nestin-expressing hair follicle cells co-expressed S100, p75 and $\beta$-III tubulin, a neuron marker. ${ }^{6}$

Immunohistochemically, the nestin-positive HAP stem cells were K15-negative and were positive for the stem-cell marker CD34, suggesting their relatively undifferentiated state. The apparent primitive state of the nestin-expressing stem cells is compatible with their apparent pluripotency.

Sieber-Blum et al. ${ }^{17}$ reported that neural-crest cells resided in the outer-root sheath from the bulge to the matrix at the base of the follicle. Bulge explants from adult mouse vibrissal follicles yielded migratory neural crest cells, including neurons, smooth muscle cells, rare Schwann cells, and melanocytes. Although the origin of the cells was not clearly defined by Sieber-Blum et al., ${ }^{17}$ the neural crest cells that they described appear to be the same cells as the nestin-expressing bulge cells we had previously discovered. ${ }^{18}$

\section{HAP stem cells in the skin produce blood vessels}

Blood vessels in the skin express ND-GFP and originate from hair-follicle cells during the anagen phase in ND-GFP mice. ${ }^{18}$ The ND-GFP vessels emerging from follicles help vascularize the dermis. The follicular origin of the blood vessels was most evident when transplanting ND-GFP-labeled follicles to unlabeled nude mice in which fluorescent new blood vessels originated only from the ND-GFP-labeled follicles.

\section{HAP stem cells differentiate to multiple types of cells}

HAP stem cells differentiate to multiple types of cells: nerve cells including, adipocytes, glial cells, keratinocytes, smooth muscle cells, cardiac muscle cells, melanocytes, osteocytes and chondrocytes. ${ }^{19,20}$ Moreover, HAP stem cells can regenerate the epidermis. The differentiation potential of HAP stem cells is greatest in the upper part of the follicle, which can produce large amounts of these stem cells (Fig. 1). ${ }^{21}$

\section{Implanted HAP stem cells enhance repair of severed peripheral nerves and the spinal cord}

GFP-expressing HAP stem cells were transplanted between severed sciatic-nerve fragments of C57BL/6 immunocompetent mice. The transplanted HAP stem cells differentiated into GFAP-positive Schwann cells. The Schwann stem cells formed

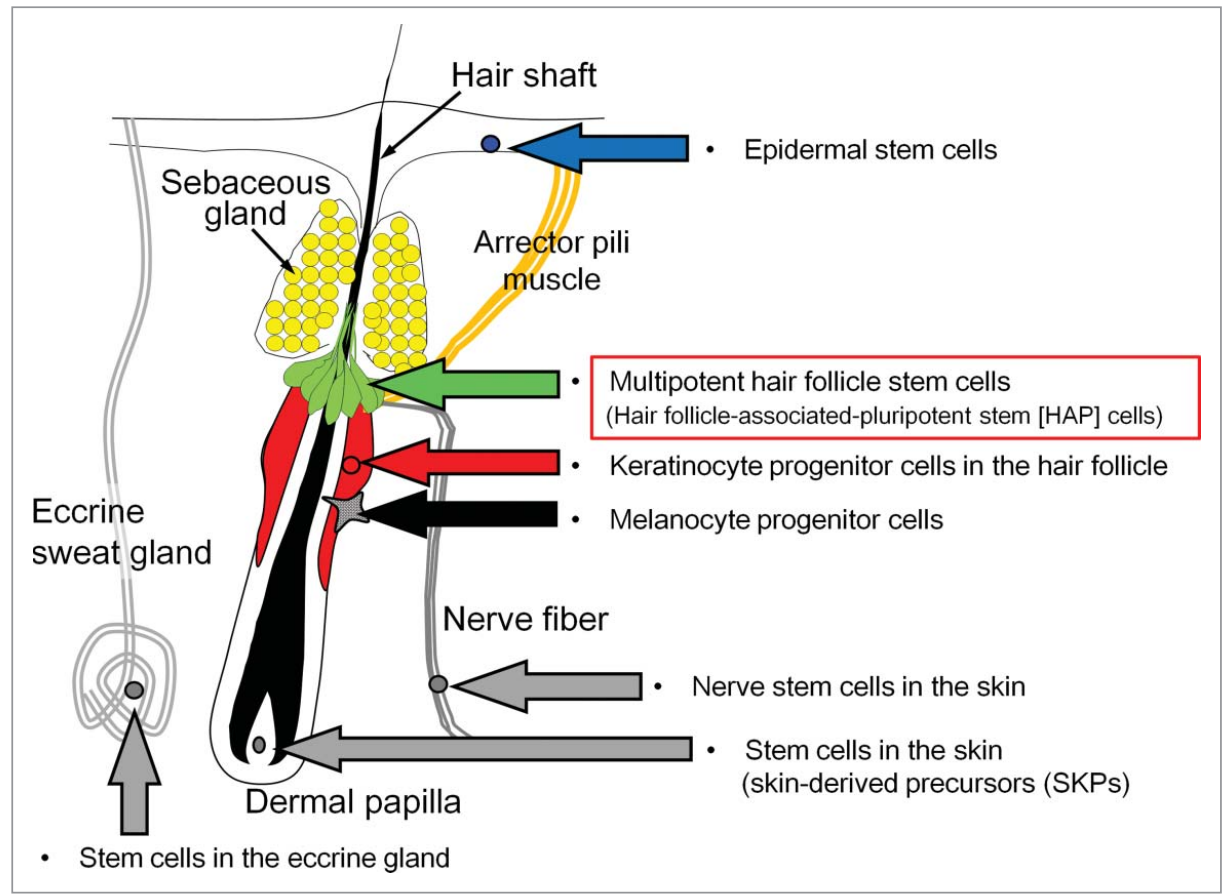

Figure 1. The location of various types of stem cells in the skin. 
myelin sheaths in the severed sciatic nerve. GFP-expressing HAP stem cells promoted the axonal growth of pre-existing neurons (Figs. 2, 3). ${ }^{22}$ The recovered sciatic nerve contracted the gastrocnemius muscle after electric stimulation. Walking print length and intermediate toe spread were also significantly recovered. $^{23,24}$ When HAP stem cells were transplanted into the gap region of severed thoracic and lumbar regions of the spinal cord, the HAP stem cells differentiated into Schwann cells. Subsequently, the thoracic and lumbar regions of spinal cord rejoined and the mice partially regained the ability to utilize their hind legs enabling them to walk. ${ }^{24}$

\section{HAP stem cells differentiate to beating cardiac-muscle cells}

We observed the unexpected result that HAP stem cells differentiated to beating cardiac muscle cells. ${ }^{25,26}$ The differentiation potential to cardiac muscle is greatest in the upper part of the follicle. The cardiac-muscle cells could beat in DMEM, containing isoproterenol, activin A, bone morphogenetic protein 4 (BMP4), and basic fibroblast growth factor $(\beta F G F)$ as well as fetal bovine serum (FBS) (Fig. 4, Movie $\mathrm{S} 1$ ). Isoproterenol directed HAP stem cells to differentiate to cardiac muscle cells, and the further addition of activin $\mathrm{A}, \mathrm{BMP} 4$, and $\beta \mathrm{FGF}$ resulted in the formation of beating cardiac-muscle tissue sheets. ${ }^{26,27}$

\section{In situ role of HAP stem cells}

Vibrissa hair follicles from ND-GFP mice, including their sensory nerve stump, were placed in $3 \mathrm{D}$ Gelfoam histoculture. $\beta$-III tubulin-positive fibers, consisting of ND-GFP-expressing cells, grew up to $500 \mu \mathrm{m}$ from the whisker nerve stump. We demonstrated F-actin in the growth in fibers which therefore appears to be growing axons. The ND-GFP cells played a major role in nerve fiber growth. Interaction with other nerves in $3 \mathrm{D}$ culture, including the sciatic nerve, the trigeminal nerve, and the trigeminal nerve ganglion were observed. ${ }^{6}$

\section{Human HAP (hHAP) stem cells}

We observed that the upper part of human hair follicle could differentiate to neurons, glial cells, keratinocytes, smooth muscle cells, and cardiac muscle cells (Fig. 5). ${ }^{28,29}$ $\mathrm{Yu}$ et $\mathrm{al}^{2}$ also reported that human hair follicles contain a nestin-expressing stem cell population that can be differentiated into neuron, smooth muscle cell, and melanocyte lineages starting from cloned cells. The human HAP (hHAP) stem cells express embryonic stem cell transcription factors Nanog and Oct4. ${ }^{2}$ When hHAP stem cells were transplanted between severed sciatic nerve fragments of the mouse, they differentiated into GFAP-positive Schwann

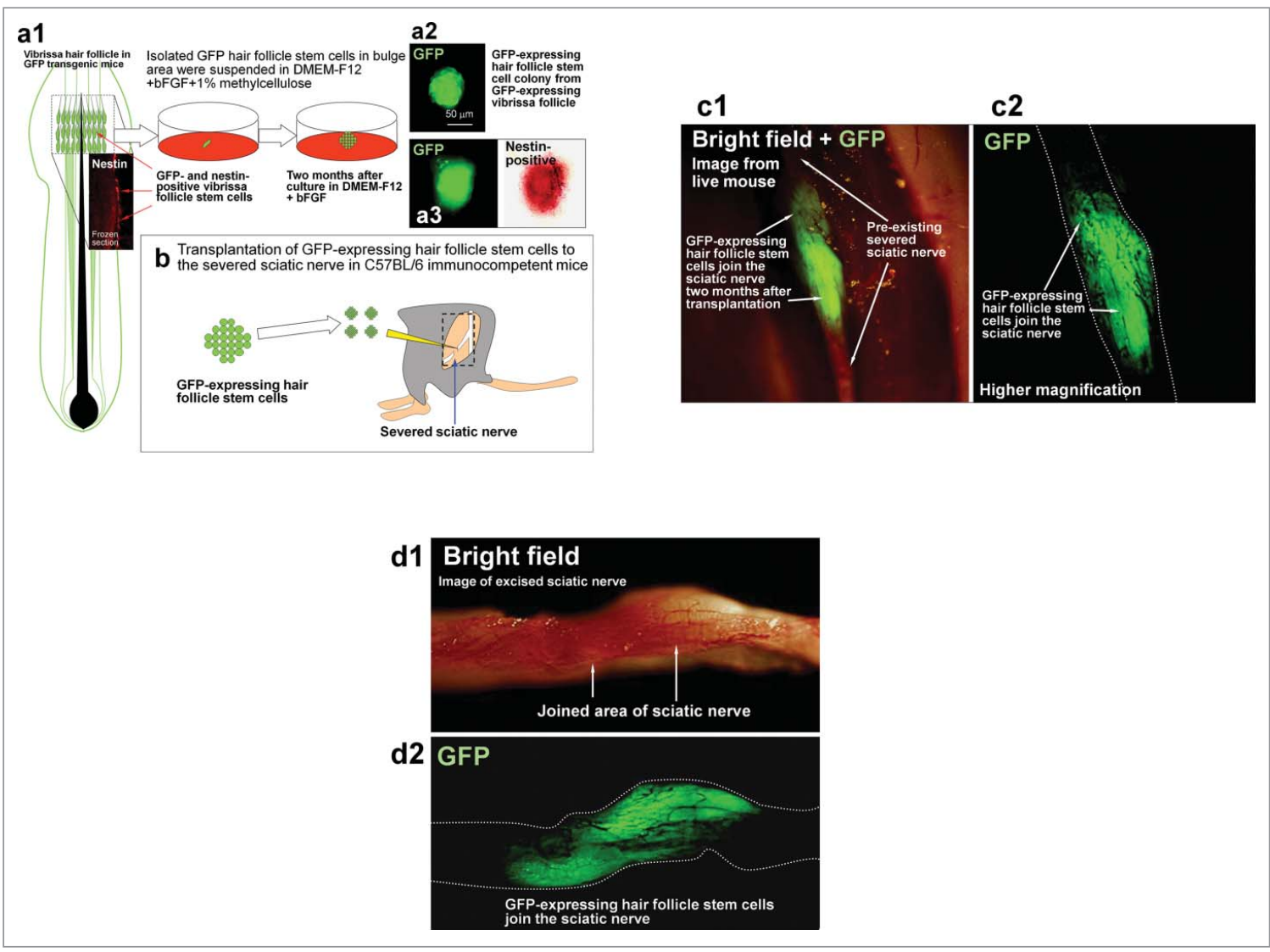

Figure 2. Rejoining severed sciatic nerves with HAP stem cells. ${ }^{12}$ (a) Schematic of vibrissa follicle of GFP transgenic mice showing the position of GFP- and nestin-expressing vibrissa follicle HAP stem cells (red arrows) (a1). Colony formed from GFP-expressing HAP stem cells from the vibrissa after 2 months in culture (a2). GFP-expressing HAP stem cells within the colony were nestin-positive (a3). (b) GFP-expressing HAP stem cells grown for 2 months in DMEM-F12 containing B-27, 1\% methylcellulose, and bFGF were transplanted between the severed sciatic nerve fragments in C57BL/6 immunocompetent mice (blue arrow). (c) Fluorescence images from a live mouse. Two months after transplantation between the severed sciatic nerve, the GFP-expressing HAP stem cells joined the severed sciatic nerve. (c2) Higher magnification of (c1). (d) Bright field (d1) and fluorescence (d2) images of an excised sciatic nerve. 


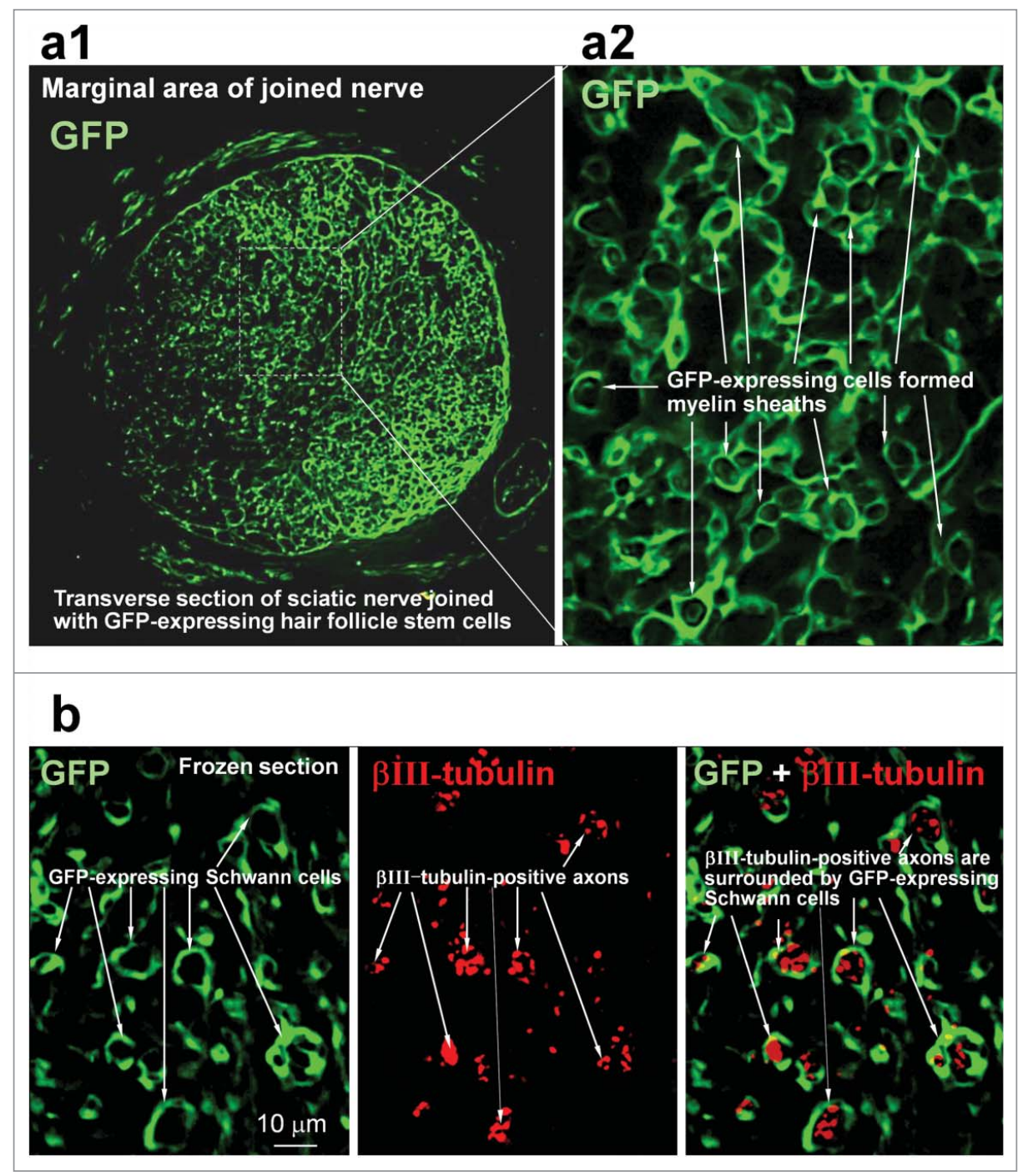

Figure 3. GFP-expressing vibrissa HAP stem cells were growing in the joined sciatic nerve. ${ }^{12}$ (a) Transverse section of joined nerve. In the marginal area of the joined nerve, GFP-expressing HAP stem cells formed many myelin sheaths (white arrows). (a2) Higher magnification of area of (a1) indicated by the white dashed box. (b) Most of the GFP-expressing vibrissa HAP stem cells differentiated to Schwann cells and formed myelin sheaths surrounding axons.

cells which promoted the recovery of pre-existing axons. ${ }^{30}$ The hHAP stem cells can be readily isolated from the human scalp.

\section{Lgr6 stem cells}

Snippert et al. ${ }^{31}$ established transgenic mice with knock-in alleles of murine Lgr6, related to the Lgr5 stem cell gene. Lgr6 was expressed in embryonic hair placodes. In adult hair follicles, Lgr6-expressing cells resided above the follicle bulge. Prenatally, Lgr6 $^{+}$cells established the hair follicle, sebaceous gland, and interfollicular epidermis. Postnatally, Lgr6 $^{+}$cells generated the sebaceous gland and the interfollicular epidermis, but contribution to hair lineages gradually diminished with age. Adult Lgr6-expressing cells executed long-term wound repair, including the formation of new hair follicles. ${ }^{31}$

Lgr6 expressing cells co-express cytokeratins (Ck18, Ck19), and multipotent stem cell markers (nestin, Sca-1, Bcrp1, and P75NTR (neurotrophin receptor) and can differentiate into mesenchymal lineages including adipocytes, chondrocytes, and muscle cells as well as neurons. ${ }^{32}$ These results suggest that the Lgr6 expressing cells are may be closely related to HAP stem cells.

\section{HAP-like stem cells in the sciatic nerve}

The ND-GFP cells of the sciatic nerve were found to be similar to the ND-GFP cells in the hair follicle. ND-GFP stem cells were observed extending the sciatic nerve in Gelfoam histoculture. The fibers contained ND-GFP-expressing spindle cells, which co-expressed the neuron marker $\beta$-III tubulin, as well as the immature Schwann-cell marker p75NTR. ${ }^{33}$

\section{Cryopreservation of the hair follicle maintains pluripotency of HAP stem cells}

We cryopreserved the whole hair follicle from GFP transgenic mice by slow-rate cooling using a protective medium (DS Pharma Biomedical Co.) and storage in liquid nitrogen. Thawed cryopreserved HAP stem cells from the 


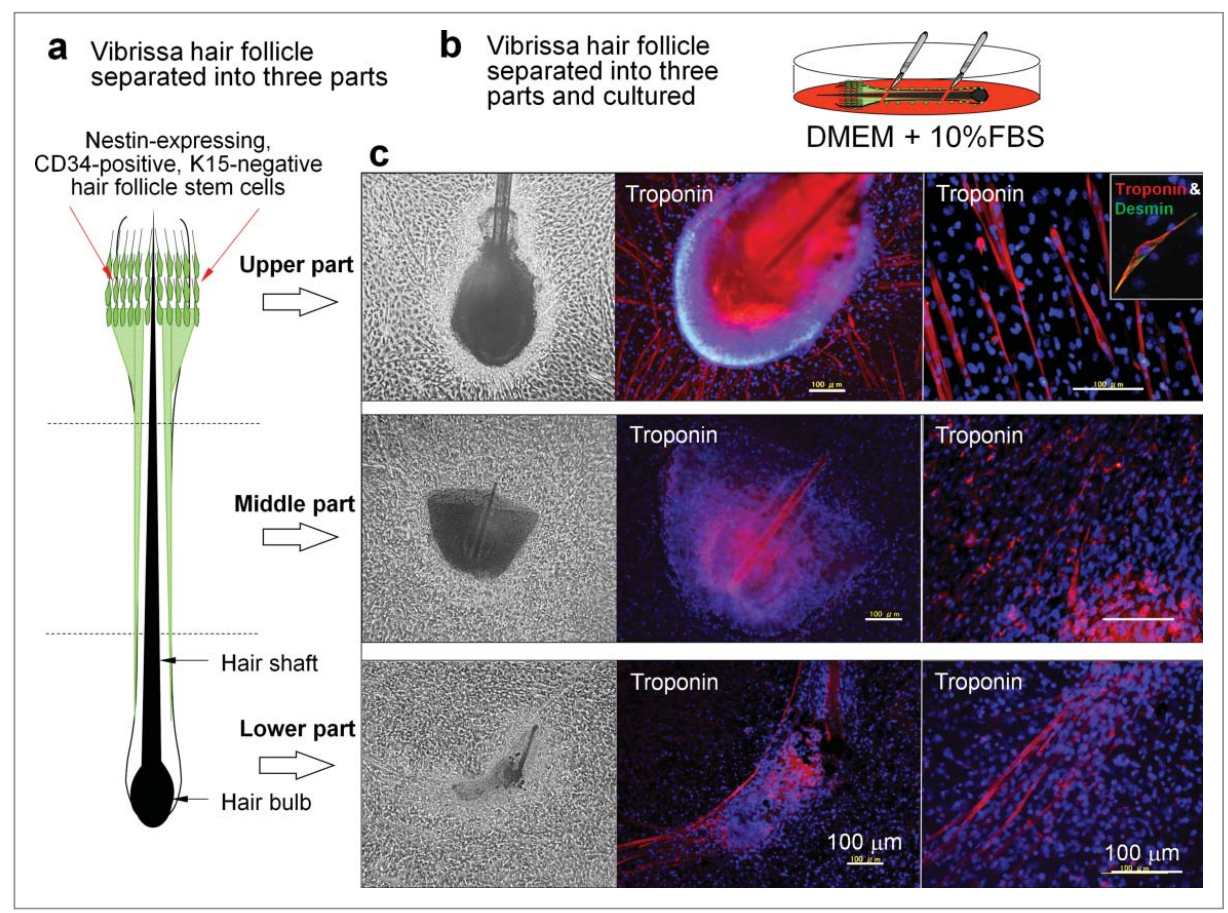

Figure 4. Mouse HAP stem cells differentiated to beating cardiac muscle cells. ${ }^{18}$ (a) Schematic of separated vibrissa hair follicle. (b) The mouse vibrissa hair follicle was separated into 3 parts (upper, middle, and lower part), and suspended separately in DMEM containing 10\% FBS. (c) Two weeks after culture, all 3 parts (upper, middle, and lower part) of the hair follicle, cultured in DMEM with FBS, differentiated to troponin- and desmin-positive cardiac muscle cells. The number of cardiac-muscle cells was significantly higher in the upper part compared with the middle and lower parts of the hair follicle. Bars $=100 \mu \mathrm{m}$.

cultured upper part of the hair follicle produced almost as many HAP stem cell colonies as fresh follicles. HAP stem cell colonies derived from cryopreserved hair follicles were as pluripotent as HAP stem cell colonies from fresh hair follicles. Thus, HAP stem cells have the potential for personalized regenerative medicine, enabling any individual to maintain a bank of cryopreserved pluripotent stem cells for future clinical use. ${ }^{29}$

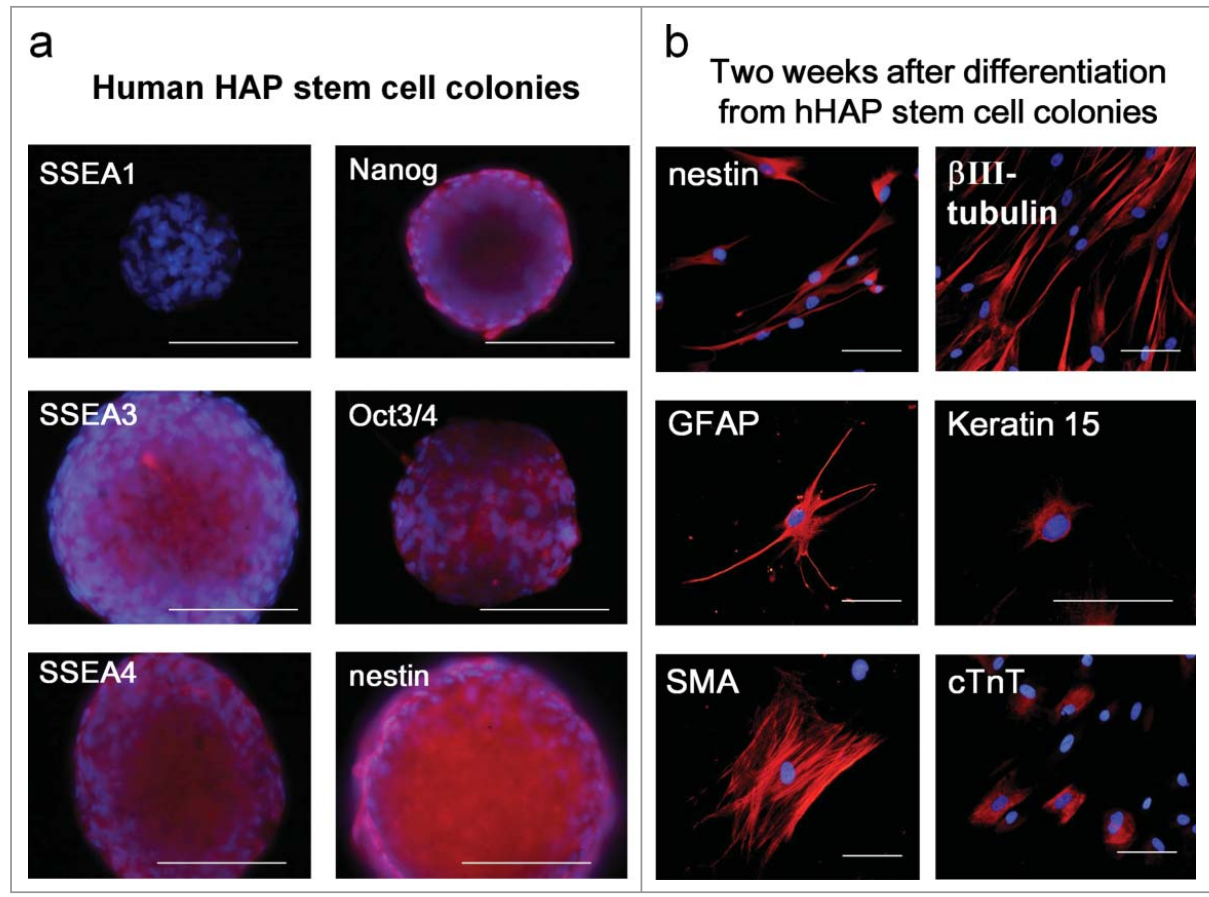

Figure 5. Nestin-expressing human HAP (hHAP) stem cell colonies differentiated to cardiac muscle and other types of cells. ${ }^{31}$ (a) hHAP stem cell colonies are SSEA1-negative, SSEA3-, SSEA4-, Nanog-, Oct3/4-, and nestin-positive. ${ }^{29}$ Scale bar $=100 \mu \mathrm{m}$. (b) Two weeks after transfer to DMEM containing $10 \%$ FBS, the nestin-expressing hHAP stem-cell colonies differentiated to nestin- and $\beta$ III-tubulin-positive neurons, GFAP-positive glial cells, K15-positive keratinocytes, smooth muscle actin-positive smooth muscle cells, and troponin (cTnT)-positive cardiac-muscle cells. Scale bar $=100 \mu \mathrm{m}$. 


\section{Issues}

A number of laboratories have performed gene-expression analysis on the hair-follicle stem cells, identifying stem-cellrelated gene expression, such as nestin, Nanog, OCT4, Sox-2 as well as differentiation markers ${ }^{19,34}$ including human hair follicles stem cells. ${ }^{35}$ The gene-expression data are complimentary to the immunohistochemistry data describe above.

There is controversy regarding "pluripotent" vs "multipotent" designations. We have used the term "pluripotent" since numerous cell types and lineages have shown to differentiate from nestin-expressing hair follicle stem cells including adipocytes, smooth muscle cells, melanocytes, neurons, glial cells, epithelial cells, vascular cells, ${ }^{2,10,17,34-36}$ osteocytes and chondrocytes, ${ }^{19,20}$ and heart muscle cells. ${ }^{25-27}$

In addition, as briefly mentioned above, the hair follicle cells express transcription factors found in embryonic stem (ES) cells that are considered "pluripotent" transcription factors by some authors. These transcription factors included OCT4, Nanog, Sox-2, AKP, and TERT. ${ }^{19,34,35}$ It should be noted that pioneering authors in the field have termed hair-follicle stem cells "pluripotent." ${ }^{17}$ Other authors may prefer the term "multipotent."

Regarding "repair," use of the HAP stem cells in the authors' laboratories have resulted in joining the severed sciatic nerve, ${ }^{22,23}$ and the spinal cord. ${ }^{24,37}$ After implantation of the stem cells, the animals regained function, with apparent sufficient recovery of the sciatic nerve to allow effective nerve transmission to cause contraction of the gastrocnemius muscle. In the case of the spinal cord repair, there was not complete recovery, but a significantly increased Basso, Beattie and Bresnahan (BBB) locomotor rating scale.

In addition, Najafzadeh et al. $^{38}$ showed that nestinexpressing rat HAP stem cells, which differentiated to neuronal and glial, could be used to promote recovery following spinal cord injury. Recovery of hind limb locomotor function in spinal-cord-injured rats, at 8 weeks following HAP stem cell transplantation was demonstrated using the BBB scale.

\section{Conclusion}

Data from multiple laboratories have shown that HAP stem cells form neurons, glial cells, endothelial cells, smooth muscle cells, melanocytes, cardiac-muscle cells, adipocytes and osteocytes $^{2,3,10,17,20,39}$ suggesting pluripotency.

$\mathrm{Yu}$ et $\mathrm{al}^{2}$ and Mignone et al. ${ }^{3}$ have described the selfrenewal of human HAP (hHAP) stem cells. For example, Yu et al. ${ }^{2}$ performed limited dilution assays to show single HAP stem cells derived from hair spheres were able to re-form spheres thus demonstrating self-renewal.

HAP stem cells induced the repair of nerves and the spinal cord as they were not repaired without implantation of HAP stem cells. $^{22,24,30,32}$

HAP-stem-cells-derived cardiac muscle cells expressed cardiac troponin $\mathrm{T}$, displayed beating behavior modified by isoproterenol and propranolol response, thereby indicating function. ${ }^{25,26}$

HAP stem cells are readily accessible from hair follicles and they do not require genetic manipulation and they do not form tumors. These are all advantages over iPS and ES cells. ${ }^{40}$

\section{Disclosure of potential conflicts of interest}

No potential conflicts of interest were disclosed.

\section{Funding}

This work was partially supported by Grant-in-Aid for Scientific Research (C) 16K10173 from the Ministry of Education, Science, Sports, and Culture of Japan, a grant from the Ministry of Education, Culture, Sports, Science, and Technology of the Japan Government (Assistance for Strategic Creation of Research Basis, 2009-2013), and the Terumo Life Science Foundation (to Y. Amoh) and the Natl. Inst. of Neurological Disorders and Stroke grant NS086217.

\section{References}

[1] Blanpain C, WE Lowry, A Geoghegan, Polak L, Fuchs E. Selfrenewal, multipotency, and the existence of two cell populations within an epithelial stem cell niche. Cell. 2004;118:635-48. https:// doi.org/10.1016/j.cell.2004.08.012. PMID:15339667.

[2] Yu H, D Fang, SM Kumar, L Li, TK Nguyen, G Acs, M Herlyn, X Xu. Isolation of a novel population of multipotent adult stem cells from human hair follicles. Am J Pathol. 2006;168:1879-88. https://doi.org/ 10.2353/ajpath.2006.051170. PMID:16723703.

[3] Mignone JL, Roig-Lopez JL, Fedtsova N, Schones DE, Manganas LN, Maletic-Savatic M, Keyes WM, Mills AA, Gleiberman A, Zhang MQ, Enikolopov G. Neural potential of a stem cell population in the hair follicle. Cell Cycle. 2007;6:2161-70. https://doi.org/10.4161/ cc.6.17.4593. PMID:17873521.

[4] Cotsarelis G, T Sun, RM Lavker. Label-retaining cells reside in the bulge area of pilosebaceous unit: Implications for follicular stem cells, hair cycle, and skin carcinogenesis. Cell. 1990;61:1329-37. https://doi. org/10.1016/0092-8674(90)90696-C. PMID:2364430.

[5] Nishimura EK, JA Jordan, H Oshima, Yoshida H, Osawa M, Moriyama M, Jackson IJ, Barrandon Y, Miyachi Y, Nishikawa S. Dominant role of the niche in melanocyte stem-cell fate determination. Nature. 2002;416:854-60. https://doi.org/10.1038/416854a. PMID:11976685.

[6] Mii S, J Duong, Y Tome, A Uchugonova, F Liu, Y Amoh, N Saito, K Katsuoka, RM Hoffman. The role of hair follicle nestin-expressing stem cells during whisker sensory-nerve growth in long-term 3D culture. J Cell Biochem. 2013;114:1674-84. https://doi.org/10.1002/ jcb.24509. PMID:23444061.

[7] Nagel S, F Rohr, C Weber, J Kier, F Siemers, C Kruse, S Danner, M Brandenburger, AE Matthiessen. Multipotent nestin-positive stem cells reside in the stroma of human eccrine and apocrine sweat glands and can be propagated robustly in vitro. PLoS One. 2013;8:e78365. https:// doi.org/10.1371/journal.pone.0078365. PMID:24205211.

[8] Toma JG, M Akhavan, JL Fernandes, F Barnabé-Heider, A Sadikot, DR Kaplan, FD Miller. Isolation of multipotent adult stem cells from the dermis of mammalian skin. Nat Cell Biol. 2001;3:778-84. https:// doi.org/10.1038/ncb0901-778. PMID:11533656.

[9] Fernandes KJL, IA McKenzie, P Mill, KM Smith, M Akhavan, F Barnabé-Heider, J Biernaskie, A Junek, NR Kobayashi, JG Toma, et al. A dermal niche for multipotent adult skin-derived precursor cells. Nat Cell Biol. 2004;6:1082-93. https://doi.org/10.1038/ncb1181. PMID:15517002.

[10] Amoh Y, L Li, K Katsuoka, S Penman, RM Hoffman. Multipotent nestin-positive, keratin-negative hair follicle bulge stem cells can form neurons. Proc Natl Acad Sci USA. 2005;102:5530-34. https:// doi.org/10.1073/pnas.0501263102. PMID:15802470.

[11] Paus R, G Cotsarelis. The biology of hair follicles. N Engl J Med. 1999;341:491-97. https://doi.org/10.1056/NEJM199908123410706. PMID:10441606.

[12] Taylor G, MS Lehrer, PJ Jensen, T-T Sun, RM Lavker. Involvement of Follicular stem cells in forming not only the follicle but also the epidermis. Cell. 2000;102:451-61. https://doi.org/10.1016/S00928674(00)00050-7. PMID:10966107.

[13] Oshima H, A Rochat, C Kedzia, K Kobayashi, Y Barrandon. Morphogenesis and renewal of hair follicles from adult multipotent stem 
cells. Cell. 2001;104:233-45. https://doi.org/10.1016/S0092-8674(01) 00208-2. PMID:11207364.

[14] Morris RJ, Y Liu, L Marles, Z Yang, C Trempus, S Li, JS Lin, JA Sawicki, G Cotsarelis. Capturing and profiling adult hair follicle stem cells. Nat Biotechnol. 2004;22:411-17. https://doi.org/ 10.1038/nbt950. PMID:15024388.

[15] Nishimura EK, SR Granter, DE Fisher DE. Mechanisms of hair graying: Incomplete melanocyte stem cell maintenance in the niche. Science. 2005;307:720-24. https://doi.org/10.1126/science.1099593. PMID:15618488.

[16] Mehnert JM, Kisch T, Brandenburger M. Co-culture systems of human sweat gland derived stem cells and peripheral nerve cells: An in vitro approach for peripheral nerve regeneration. Cell Physiol Biochem. 2014;34:1027-37. https://doi.org/10.1159/000366318. PMID:25227895.

[17] Sieber-Blum M, M Grim, YF Hu, R Schneider, ME Schwab. Pluripotent neural crest stem cells in the adult hair follicle. Dev Dyn. 2004;231:258-69. https://doi.org/10.1002/dvdy.20129. PMID:15366003.

[18] Li L, J Mignone, M Yang, M Matic, S Penman, G Enikolopov, RM Hoffman. Nestin expression in hair follicle sheath progenitor cells. Proc Natl Acad Sci USA. 2003;100:9958-61. https://doi.org/10.1073/ pnas.1733025100. PMID:12904579.

[19] He N, Dong Z, Zhu B, Nuo M, Bou S, Liu D. Expression of pluripotency markers in Arbas Cashmere goat hair follicle stem cells. In Vitro Cell Dev Biol Anim. 2016;52:782-88. https://doi.org/10.1007/ s11626-016-0023-3. PMID:27364919.

[20] Urano-Morisawa E, Takami M, Suzawa T, Matsumoto A, Osumi N, Baba $\mathrm{K}$, Kamijo R. Induction of osteoblastic differentiation of neural crestderived stem cells from hair follicles. PLoS One. 2017;12:e0174940. https://doi.org/10.1371/journal.pone.0174940. PMID:28384239.

[21] Amoh Y, S Mii, R Aki, Y Hamada, K Kawahara, RM Hoffman, K Katsuoka. Multipotent nestin-expressing stem cells capable of forming neurons are located in the upper, middle, and lower part of the vibrissa hair follicle. Cell Cycle. 2012;11:3513-17. https://doi.org/ 10.4161/cc.21803. PMID:22918245.

[22] Amoh Y, L Li, R Campillo, K Kawahara, K Katsuoka, S Penman, RM Hoffman. Implanted hair follicle stem cells form Schwann cells which support repair of severed peripheral nerves. Proc Natl Acad Sci USA. 2005;102:17734-738. https://doi.org/10.1073/ pnas.0508440102. PMID:16314569.

[23] Amoh Y, Aki R, Kawahara K, Hamada Y, Hoffman RM, Katsuoka K. Direct transplantation of uncultured hair follicle pluripotent stem (hfPS) cells promote the recovery of peripheral nerve injury. J Cell Biochem. 2010;110:272-77. https://doi.org/10.4161/cc.7.12.6056. PMID:20411592.

[24] Amoh Y, L Li, K Katsuoka, RM Hoffman. Multipotent hair follicle stem cells promote repair of spinal cord injury and recovery of walking function. Cell Cycle. 2008;7:1865-69. https://doi.org/10.4161/ cc.7.12.6056. PMID:18583926.

[25] Yashiro M, S Mii, R Aki, Y Hamada, N Arakawa, K Kawahara, RM Hoffman, Y Amoh. From hair to heart: Hair follicle stem cells differentiate to beating cardiac muscle cells. Cell Cycle. 2015;14:2362-66. https://doi.org/10.1080/15384101.2015.1042633. PMID:25970547.

[26] Yamazaki A, M Yashiro, S Mii, R Aki, Y Hamada, N Arakawa, K Kawahara, RM Hoffman, Y Amoh. Isoproterenol directs hair follicleassociated pluripotent (HAP) stem cells to differentiate in vitro to cardiac muscle cells which can be induced to form beating heart muscle tissue sheets. Cell Cycle. 2016;15:760-65. https://doi.org/ 10.1080/15384101.2016.1146837. PMID:27104748.

[27] Yamazaki A, Y Hamada, N Arakawa, M Yashiro, S Mii, R Aki, K Kawahara, RM Hoffman, Y Amoh. Early-age-dependent selective decrease of differentiation potential of hair-follicle-associated pluripotent (HAP) stem cells to beating cardiac muscle cells. Cell Cycle. 2016;15:2619-25. https://doi.org/10.1080/15384101.2016.1208870. PMID:27428074.

[28] Amoh Y, M Kanoh, S Niiyama, K Kawahara, Y Sato, K Katsuoka, RM Hoffman. Human and mouse hair follicles contain both multipotent and monopotent stem cells. Cell Cycle. 2009;8:176-77. https://doi. org/10.4161/cc.8.1.7342. PMID:19106614.

[29] Kajiura S, S Mii, R Aki, Y Hamada, N Arakawa, K Kawahara, L Li, K Katsuoka, RM Hoffman, Y Amoh. Cryopreservation of the hair follicle maintains pluripotency of nestin-expressing stem cells. Tissue Eng Part C Methods. 2015;21:825-31. https://doi.org/10.1089/ten. tec.2014.0500. PMID:25743086.

[30] Amoh Y, M Kanoh, S Niiyama, Y Hamada, K Kawahara, Y Sato, RM Hoffman, K Katsuoka. Human hair follicle pluripotent stem (hfPS) cells promote regeneration of peripheral-nerve injury: An alternative to ES and iPS cells. J Cell Biochem. 2009;107:1016-20. https://doi. org/10.1002/jcb.22204. PMID:19507228.

[31] Snippert HJ, A Haegebarth, M Kasper, V Jaks, JH van Es, N Barker, $M$ van de Wetering, $M$ van den Born, $H$ Begthel, RG Vries, et al. Lgr6 marks stem cells in the hair follicle that generate all cell lineages of the skin. Science. 2010;327:1385-89. https://doi.org/10.1126/ science.1184733. PMID:20223988.

[32] Nath M, M Offers, M Hummel, J Seissler. Isolation and in vitro expansion of Lgr6-positive multipotent hair follicle stem cells. Cell Tissue Res. 2011;344:435-44. https://doi.org/10.1007/s00441-0111165-y. PMID:21484413.

[33] Mii S, F Uehara, S Yano, B Tran, S Miwa, Y Hiroshima, Y Amoh, K Katsuoka, RM Hoffman. Nestin-expressing stem cells promote nerve growth in long-term 3-dimensional Gelfoam ${ }^{\circledR}$ - supported histoculture. PLoS One. 2013;8:e67153. https://doi.org/10.1371/journal pone.0067153. PMID:23840607.

[34] Hu YF, Zhang ZJ, Sieber-Blum M. An epidermal neural crest stem cell (EPI-NCSC) molecular signature. Stem Cells. 2006;24:2692-02. https://doi.org/10.1634/stemcells.2006-0233. PMID:16931771.

[35] Yu H, Kumar SM, Kossenkov AV, Showe L, Xu X. Stem cells with neural crest characteristics derived from the bulge region of cultured human hair follicles. J Invest Dermatol. 2010;130:1227-36. https:// doi.org/10.1038/jid.2009.322. PMID:19829300.

[36] Fairbairn NG, Meppelink AM, Ng-Glazier J, Randolph MA, Winograd JM. Augmenting peripheral nerve regeneration using stem cells: A review of current opinion. World J Stem Cells. 2015;7:11-26. https://doi.org/10.4252/wjsc.v7.i1.11. PMID:25621102.

[37] Liu F, Uchugonova A, Kimura H, Zhang C, Zhao M, Zhang L, Koenig K, Duong J, Aki R, Saito N, et al. The bulge area is the major hair follicle source of nestin-expressing pluripotent stem cells which can repair the spinal cord compared to the dermal papilla. Cell Cycle. 2011;10:830-39. https://doi.org/10.4161/ cc.10.5.14969. PMID:21330787.

[38] Najafzadeh N, Nobakht M, Pourheydar B, Golmohammadi MG. Rat hair follicle stem cells differentiate and promote recovery following spinal cord injury. Neural Regen Res. 2013;8:3365-72. https://doi. org/10.3969/j.issn.1673-5374.2013.36.001. PMID:25206658.

[39] Amoh Y, Li L, Yang M, Moossa AR, Katsuoka K, Penman S, Hoffman RM. Nascent blood vessels in the skin arise from nestin-expressing hair follicle cells. Proc Natl Acad Sci USA. 2004;101:13291-95. https://doi.org/10.1073/pnas.0405250101. PMID:15331785.

[40] Hoffman, RM, editor. Multipotent Stem Cells of the Hair Follicle: Methods and Protocols. Methods in Molecular Biology. Vol. 1453 Walker, John M., series editor. Humana Press (Springer Science+Business Media New York); 2016. https://doi.org/10.1007/978-14939-3786-8. 